\title{
Persistent Tracheo-cutaneous Fistula: A Case Report
}

\author{
Persistan Trakeo-kutanöz Fistül: Olgu Sunumu \\ Rajalakshmi Rajagopalan, Rabeeh Parambil, Siva Ashish, Subramaniam Suriyan
}

\begin{abstract}
Persistent tracheo-cutaneous fistula, or persistent tracheal stoma, is a potential late complication of a tracheostomy. It commonly occurs in children due to a failure of spontaneous closure after decannulation. In adults, however, this is relatively less common. Described is a case of a 38-year-old man who, despite undergoing early and successful decannulation, presented with a persistent tracheal stoma due to pulmonary tuberculosis.
\end{abstract}

Key words: Tracheo-cutaneous fistula, persistent tracheal stoma, pulmonary tuberculosis, anti-tuberculosis treatment.

\section{Özet}

Persistan trakeo-kutanöz fistül veya persistan trakeal stoma, trakeostominin geç bir komplikasyonudur. Trakeokutanöz fistül, çocuklarda, kanül çıkarıldıktan sonra trakeostominin spontan kapanmasının başarısız olmasından dolayı yaygın olarak görülmektedir. Ancak yetişkinlerde, bu nispeten daha az yaygındır. Erken ve başarılı dekanülasyona rağmen akciğer tüberkülozu nedeniyle kalıcı trakeal stoma ile başvuran 38 yaşında bir erkek hastayı sunuyoruz.

Anahtar Sözcükler: Trakeo-kutanöz fistül, persistan trakea stoması, akciğer tüberkülozu, anti-tüberküloz tedavi.
Tracheostomy is a procedure in which a surgical airway is created in the cervical trachea. It is commonly done in patients who have difficulty when removed from a ventilator, when there is an inability to protect the airway because of trauma or severe neurological damage, there is an upper airway obstruction that needs to be emergently bypassed, a life-threatening infection of the upper airway, or congenital upper airway anomalies (1). Immediate complications can include apnea, bleeding, and pneumothorax/pneumomediastinum. Potential late complications include tracheoinnominate fistula, tracheomalacia, tracheal stenosis, tracheo-esophageal fistula, and tracheacutaneous fistula (TCF).
Decannulation is performed after successful tracheostomy tube plugging overnight. The wound heals and closes spontaneously in 5 to 7 days. When the tracheostomy tract undergoes epithelialization from the skin to the tracheal mucosa, a stoma may persist as TCF. It is a delayed complication of tracheostomy, especially in the pediatric age group, with an incidence of $3.3 \%$ to $43 \%$, but is relatively less common in adults (2-5).

The most important factor that contributes to the persistence and failure of closure is the duration of cannulation $(6,7)$. Another predisposing factor is the starplasty tracheostomy technique, which was introduced in 1990 as an alternative tracheostomy technique in children (8). A tracheocutaneous

SRM Medical College Hospital \& Research Centre, Kattankulathur, India

SRM Medikal Kolej Hastanesi \& Araştırma Merkezi, Kattankulathur, Hindistan

Submitted (Başvuru tarihi): 15.04.2018 Accepted (Kabul tarihi): 01.06 .2018

Correspondence (iletişim): Rajalakshmi Rajagopalan, SRM Medical College Hospital \& Research Centre,

Kattankulathur, India

e-mail: dr.rajalakshmi@yahoo.com 
communication is intentionally created by forming a circumferential muco-cutaneous suture line between the skin and the tracheal mucosa (6).

The other predisposing factors are poor nutritional status, immunosuppression (high-dose steroids, etc.), radiotherapy, infection, granulomatous disease, distal obstruction due to bilateral vocal cord paralysis, and tracheal stenosis $(9,10)$.

Patients with TCF may suffer from recurrent aspiration and subsequent respiratory infection, difficulty in phonation, difficulty in clearing secretions, ineffective cough, difficulty swallowing, skin irritation and/or ulceration, cosmetic and social issues, and intolerance to swimming (11). This may lead to considerable discomfort, especially after successful decannulation.

Management of TCF is usually achieved with surgical excision of the fistula tract. Two techniques are available. Primary closure with drain placement offers better cosmetic healing of the scar with a higher risk of subcutaneous emphysema. Secondary closure involves excision of the fistula, replacement of a small tracheostomy tube, and subsequent decannulation, thereby ensuring healing by secondary intention and closure. This is not often done, as it is less acceptable to the patient to have another tracheostomy after decannulation, but it is a relatively safer procedure.

\section{CASE}

A 38-year-old male was attended to in the respiratory medicine department. He had undergone an emergency craniotomy and evacuation of an acute fronto-parietotemporal subdural hematoma 2 months earlier. Due to difficulty with removal of the ventilator, a tracheostomy was performed. He was successfully decannulated after 3 weeks. He had a persistent opening and non-foulsmelling discharge from the tracheostomy site for 2 weeks. He was referred for evaluation of the trachea to rule out tracheomalacia and tracheal stenosis before a planned suturing of the TCF. There was also a history of a nonproductive cough for 4 months prior to the surgery associated with weight loss and anorexia, but he had no fever and attributed his debilitation to the head injury he sustained a year earlier.

The patient had no history of tuberculosis, diabetes mellitus, hypertension, or other significant comorbidities. He was a non-smoker and only occasionally consumed alcohol. He was an electrician by occupation.

Clinical examination revealed a conscious, cooperative patient in no acute distress, with stable vital signs with a body mass index of $16.7 \mathrm{~kg} / \mathrm{m}^{2}$. He had a $2 \times 2 \mathrm{~cm}$ anterior midline opening in the suprasternal area with nonfoul smelling, purulent discharge at the tracheostomy site (Figure 1A). His lungs were clear on auscultation and other systems were within normal limits. His chest $X$-ray showed bilateral upper zone air-space opacities (Figure 2).
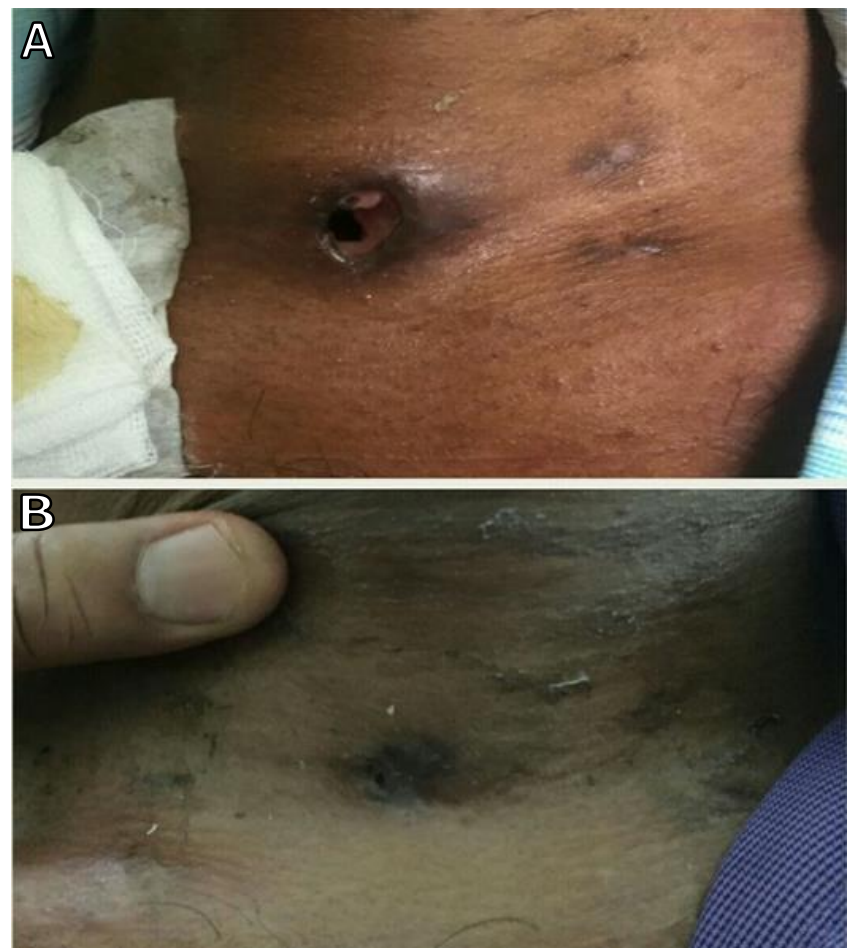

Figure 1A and B: Examination of the neck; $A$ (top) Tracheostomy site, inflammation and purulent discharge; $B$ (bottom) Tracheostomy, healed and closed, after 2 months of anti-tuberculosis therapy

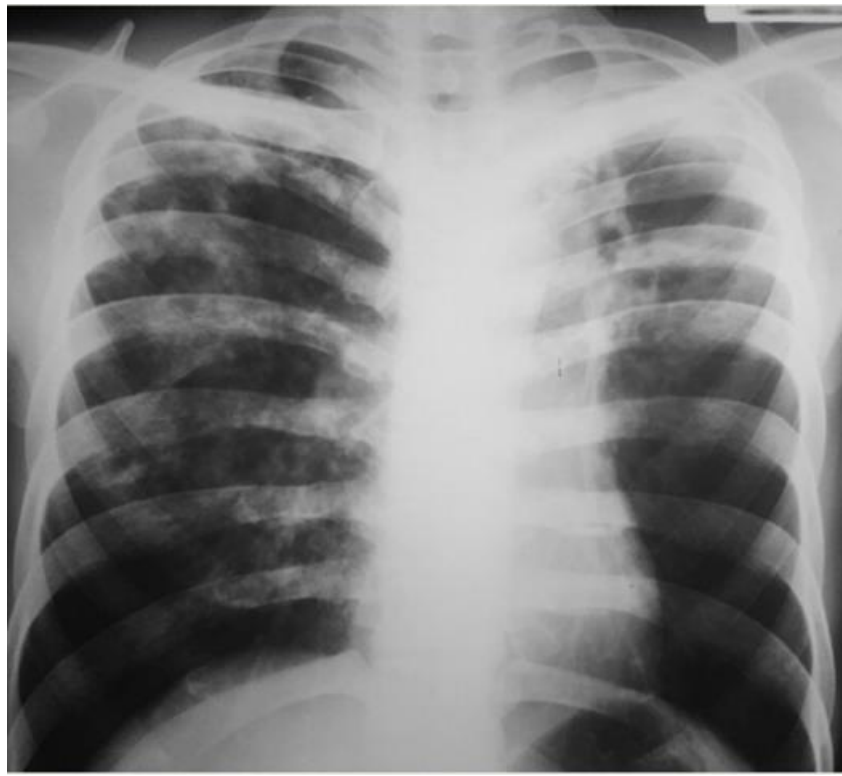

Figure 2: Chest X-ray: Right upper zone, Left upper zone opacities

He had also received a 2-week course of antibiotics for methicillin-sensitive Staphylococcus aureus grown in pus 
culture from the tracheal stoma. Since the tracheostomy wound had persisted and continued to emit discharge, and as he could not expectorate despite sputum induction a bronchoscopy was done, which revealed unhealthy necrotic mucosa and purulent discharge around the fistulous opening and purulent secretions in the right and left upper lobe bronchi (Figure 3A). The secretions from the tracheal opening and from the upper lobes were separately sent for microbiological examination (Gram stain and cultures, acid-fast bacilli [AFB] stain, and cartridgebased nucleic acid amplification test [CB-NAAT]). Both samples showed numerous AFB, and Mycobacterium tuberculosis was detected in the CB-NAAT.

An anti-tuberculosis chemotherapy regimen of 2 (HREZ) followed by $4(\mathrm{HR})$. After 6 months of antituberculosis therapy, the tracheal stoma closed (Figure 1B) with no tracheomalacia or stenosis (Figure $3 \mathrm{~B}$ ). His chest X-ray showed good radiological clearance and his sputum was negative for AFB.
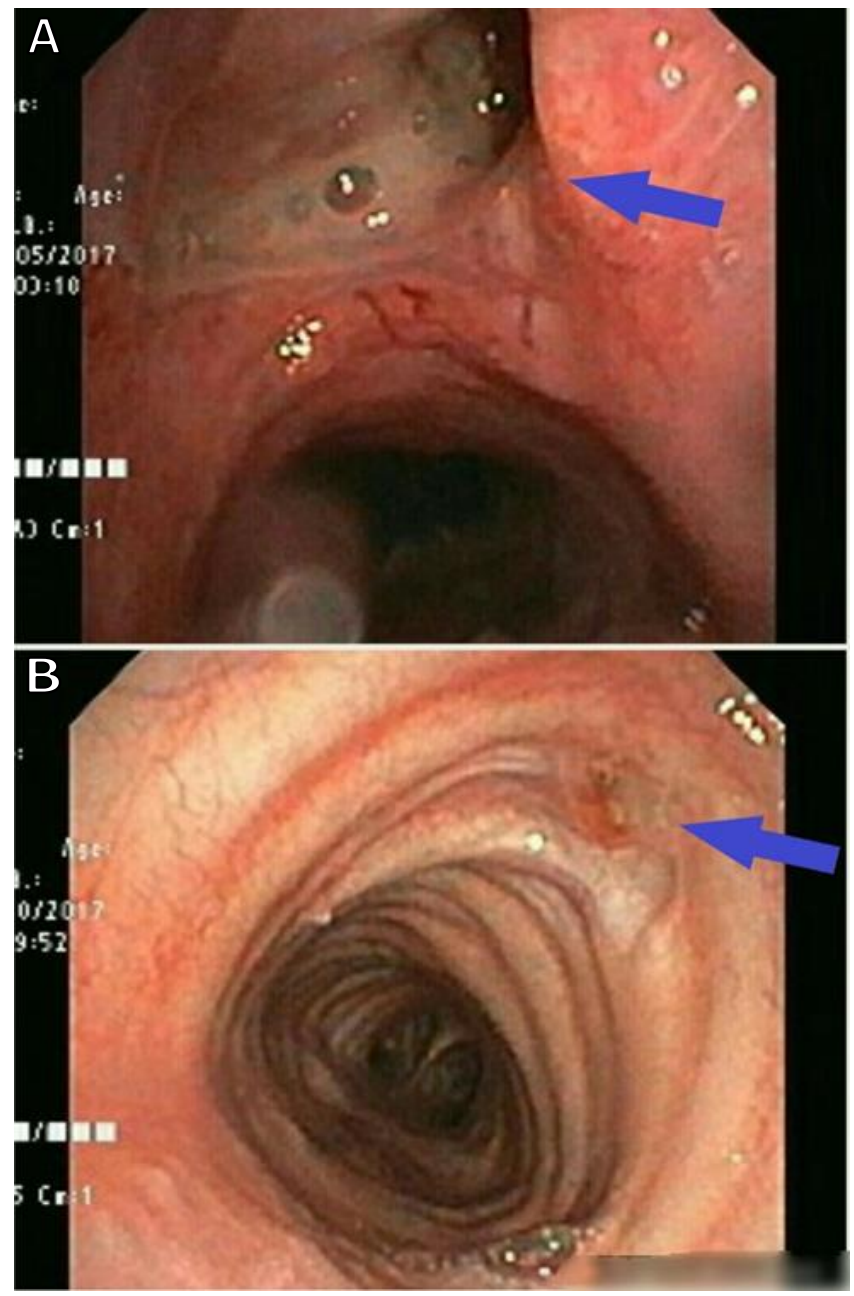

Figure 3A and B: Bronchoscopy; A (top) Tracheocutaneous fistula (solid blue arrow)with purulent secretions; $B$ (bottom): Healed and closed tracheocutaneous fistula (solid blue arrow), after 6 months of antituberculosis therapy.

\section{DISCUSSION}

While TCF is a well-known potential late complication of a tracheotomy in the pediatric age group, in adults it is relatively less common and easier to manage. The incidence rate of TCF from studies of children undergoing a tracheostomy varies from $3.3 \&$ to $43 \%$. In the 1960s, the incidence of TCF was low, at just more than $3 \%(2,3)$. The incidence has increased with the increased number of indications for a tracheostomy $(4,5)$.

According to Kubler and Passy (6), the incidence of persistent tracheal stoma is $70 \%$ if the cannulation period is 16 weeks or more, while tracheostomies close spontaneously when less than 16 weeks. In a retrospective study of 164 children performed by $\mathrm{Ha}$ et al. (12), the relative risk of TCF in a case of tracheostomy was significantly greater when longer than 24 months (risk ratio: 2.52) than for less than 12 months.

In a study conducted by Grønhøj et al. (13), neuromuscular disease was the most common indication. Of 69 tracheostomized children, 9 developed TCF or wound granulation and $53 \%$ of lower airway infections were due to Staphylococcus aureus. Nassif et al. (14) reported that of 57 patients who underwent a tracheostomy, 39 (68\%), were for upper airway obstruction and 18 (32\%) were due to prolonged ventilation. Nine cases (33\% of decannulations) had TCF that required surgery. Al-Samri et al. (4) reported that upper airway obstruction due to subglottic stenosis and craniofacial syndromes were the 2 most common indications in $15(21 \%)$ patients each, and TCF was seen in $37 \%$.

Huber et al. (15) have also reported a case of a patient with burns whose TCF healed with local wound care and without surgery.

While granulomatous infection is a known predisposing factor, cases with pulmonary tuberculosis leading to failure of spontaneous closure of a tracheostomy have not been widely reported in the literature. However, Tong and Chow (16) reported a case of tuberculous tracheitis in the absence of pulmonary parenchymal lesion presenting as TCF, which resolved with anti-tuberculosis treatment.

Our case is an example of a chronic, indolent infection, tuberculosis, as a cause of the lack of a spontaneous closure of the tracheostomy. In developing countries, tuberculosis constitutes a major healthcare burden with significant morbidity and mortality. Complications of surgical sites and tracheostomies by tuberculosis must therefore be considered in any case of delayed wound healing. Early detection and treatment can significantly 
reduce morbidity and mortality and avoid surgical closure in some cases.

\section{CONCLUSION}

Our case demonstrates an important cause of the failure or delayed closure of a tracheostomy after decannulation - pulmonary tuberculosis. The tracheostomy site bears the brunt of contaminants from the oral cavity and the lungs. The likely mechanism for tracheal stoma infection is retrograde spread of $M$. tuberculosis bacilli from the pulmonary focus. The importance of an active search for a pulmonary focus of infection, especially when the duration of cannulation is short, cannot be over-emphasized. When treated, it may obviate the need for surgery. Our case also represents the tip of the iceberg of patients with undiagnosed pulmonary tuberculosis who are a public health challenge, as they come in contact with family, healthcare providers, and society at large. In our case, universal health precautions were followed, as always. Additionally, if a patient with pulmonary tuberculosis requires life-saving emergency surgery, the operation theater will be subjected to sterilization/disinfection procedures.

\section{ACKNOWLEDGEMENT}

We thank Dr. Praveen Radhakrishnan for his valuable support.

\section{CONFLICTS OF INTEREST}

None declared.

\section{AUTHOR CONTRIBUTIONS}

Concept - R.R., R.P., S.A., S.S.; Planning and Design R.R., R.P., S.A., S.S.; Supervision - R.R., R.P., S.A., S.S.; Funding - R.R., R.P., S.A., S.S.; Materials - R.R., R.P.; Data Collection and/or Processing - R.R., R.P.; Analysis and/or Interpretation - R.R.; Literature Review - R.R.; Writing - R.R.; Critical Review - R.R., R.P., S.A., S.S.

\section{YAZAR KATKILARI}

Fikir - R.R., R.P., S.A., S.S.; Tasarım ve Dizayn - R.R., R.P., S.A., S.S.; Denetleme - R.R., R.P., S.A., S.S.; Kaynaklar R.R., R.P., S.A., S.S.; Malzemeler - R.R., R.P.; Veri Toplama ve/veya İşleme - R.R., R.P.; Analiz ve/veya Yorum R.R.; Literatür Taraması - R.R.; Yazıyı Yazan - R.R.; Eleştirel İnceleme - R.R., R.P., S.A., S.S.

\section{REFERENCES}

1. Mitchell RB, Hussey HM, Setzen G, Jacobs IN, Nussenbaum B, Dawson $C$, et al. Clinical consensus statement: tracheostomy care. Otolaryngol Head Neck Surg 2013; 148:6-20. [CrossRef]

2. Oliver P, Richardson JR, Clubb RW, Flake CG. Tracheotomy in children. N Engl J Med 1962; 267:631-7. [CrossRef]

3. Tucker JA, Silberman HD. Tracheotomy in pediatrics. Ann Otol Rhinol Laryngol 1972; 81:818-24. [CrossRef]

4. Al-Samri M, Mitchell I, Drummond DS, Bjornson C. Tracheostomy in children: a population-based experience over 17 years. Pediatr Pulmonol 2010; 45: 487-93. [CrossRef]

5. Carron JD, Derkay CS, Strope GL, Nosonchuk JE, Darrow $\mathrm{DH}$. Pediatric tracheotomies: changing indications and outcomes. Laryngoscope 2000; $110: 1099-104$.

6. Kulber H, Passy V. Tracheotomy closure and scar revisions. Arch Otolaryngol 1972; 96:22-6.

7. Bishop JB, Bostwick J, Nahai F. Persistent tracheostomy stoma. Am J Surg 1980; 140:709-10. [CrossRef]

8. Sautter NB, Krakovitz PR, Solares CA, Koltai PJ. Closure of persistent tracheocutaneous fistula following "starplasty" tracheostomy in children. Int J Pediatr Otorhinolaryngol 2006; 70:99-105. [CrossRef]

9. Tasca R, Clarke R. Tracheocutaneous fistula following paediatric tracheostomy - a 14 -year experience at Alder Hey Children's Hospital. Int J Pediatr Otorhinolaryngol 2010; 74:711-2. [CrossRef]

10. Stern Y, Cosenza M, Walner DL, Cotton RT. Management of persistent tracheocutaneous fistula in the pediatric age group. Ann Otol Rhinol Laryngol 1999; 108:880-3. [CrossRef]

11. Gallagher TQ, Hartnick CJ. Tracheocutaneous fistula closure. Adv Otorhinolaryngol 2012; 73:76-9. [CrossRef

12. Ha TA, Goyal M, Ongkasuwan J. Duration of tracheostomy dependence and development of tracheocutaneous fistula in children. Laryngoscope 2017; 127:2709-12. [CrossRef]

13. Grønhøj C, Charabi B, Buchwald CV, Hjuler T. Indications, risk of lower airway infection, and complications to pediatric tracheotomy: report from a tertiary referral center. Acta Otolaryngol 2017; 137:868-71. [CrossRef]

14. Nassif $C$, Zielinski M, Francois $M$, van den Abbeele $T$. Tracheotomy in children: A series of 57 consecutive cases. Eur Ann Otorhinolaryngol Head Neck Dis 2015; 132:321-5. [CrossRef] 
15. Huber KM, Billington AR, Taylor LJ, Maynell KB, Wayne Cruse $C$. Nonoperative treatment of a tracheocutaneous fistula in a burn patient. J Burn Care Res 2017; 38:e772-e775. [CrossRef]
16. Tong FM, Chow SK. Primary tuberculous tracheitis. J Laryngol 1998; 112:579-80. [CrossRef] 